\title{
In vitro antifungal activity of Candida culture extracts against Trichophyton rubrum and Trichophyton mentagrophytes
}

\begin{abstract}
Thiago Henrique Lemes 1, Guilherme Silva Torrezan 1, Carlos Roberto Polaquini 1, Luis Octavio Regasini 1, Bianca Gottardo de Almeida 1, Natália Seron Brizzotti-Mazuchi 2, Mariela Domiciano Ribeiro 2, Taiza Maschio-Lima 1, Maicon Henrique Caetano 1, Veridianna Camilo Pattini 1, Mario Henrique Paziani 3, Marcia Regina von Zeska Kress 3, João Paulo Zen Siqueira 2, Margarete Teresa Gottardo Almeida 2
\end{abstract}

${ }^{1}$ São Paulo State University (UNESP), Institute of Biosciences, Humanities and Exact Sciences (Ibilce), São Paulo, SP, Brazil.

${ }^{2}$ Department of Infectious, Parasitary and Dermatology Diseases, São José do Rio Preto Medical School (Famerp), São Paulo, SP, Brazil.

${ }^{3}$ Department of Clinical Analysis, Toxicology and Food Sciences, School of Pharmaceutical Sciences of Ribeirão Preto, University of São Paulo (USP), São Paulo, SP, Brazil.

*Corresponding author: Thiago Henrique Lemes. Av. Brigadeiro Faria Lima, - 5416 - Vila São Pedro CEP: 15090000, São Paulo, SP, Brazil. Phone: +55 (17) 32015843. E-mail: th.lemes@unesp.br.

Research Ethics Committee Approval: Not applicable.

Received on: Oct 11, 2021. Accepted on: Oct 31, 2021. Available online: Nov 15, 2021.

\begin{abstract}
Onychomycoses are nail infections caused primarily by dermatophytes fungi, yeasts, and other filamentous fungi, characterized by persistent infections, prolonged therapy, and high recurrence rates. In clinical practice, some of these occurrences present two or more microorganisms, and the interactions among them can change the chemical environment mediated by small diffusible molecules, producing a competitive niche. The aim of this study was to evaluate the antifungal activity of individual extracts of pure cultures of Candida albicans and C. parapsilosis against dermatophytes. To obtain the fungal extracts, cultures were filtered through a $0.2 \mu \mathrm{m}$ membrane and submitted to liquid-liquid extraction using ethyl acetate. The Minimal Inhibitory Concentration (MIC) of each extract was evaluated by broth microdilution method and checkerboard assay with fluconazole against clinical isolates of Trichophyton rubrum and T. mentagrophytes. The invertebrate model of Galleria mellonella was used to evaluate the toxicity of the extracts. As results, the extracts of C. albicans and C. parapsilosis showed antifungal activity with MICs between 31,2 $2000 \mu \mathrm{g} / \mathrm{mL}$. In association with fluconazole, synergistic effect was detected for all combinations. The extracts presented low toxicity in G. mellonella. In the future, isolation and identification of the extract compounds may allow new therapeutic approaches in the control of fungal infections.
\end{abstract}

Abstract

Keywords: Onychomycoses; Dermatophytes; Yeast; Antifungal activity. 


\section{Introduction}

Onychomycoses are nail infections caused by dermatophytes, yeasts, and other non-dermatophytes moulds. They are responsible for $50 \%$ of all nail diseases and $30 \%$ of cutaneous fungal infections [1]. It is a public health problem, which generates high cost to the health services and psychosocial impact, decreasing work productivity and quality of life to the patients $[2,3]$. These nail infections are characterized by high-rate recurrence with a prolonged therapy, with irreversible damage to the nail plate. This event contributes to the emergence of microorganisms resistant to conventional antifungals, which may cause refractory fungal diseases $[4,5]$. In addition, the limited antifungal drugs arsenal and the potential side effects, including hepatotoxic damage, contribute to high morbidity rates [6-8].

Dermatophytes are the main etiologic agents of onychomycosis, especially Trichophyton mentagrophytes and T. rubrum species. Moreover, Candida, mostly C. albicans and $C$. parapsilosis, can also be associated with nail infections, especially fingernails [9]. Interactions between yeasts and dermatophytes in nails diseases may occur in cases of mixed infections or colonization, in which competition or cooperation can alter disease progression. Small diffusible molecules are produced and can mediate these interactions inside nail matrix and affect the survival of these microorganisms in this environment [10]. The mechanisms involved should be explored, once these antifungal molecules can constitute therapeutic alternatives against fungal infections [11-13]. The aim of this work was to evaluate the in vitro antifungal activity of Candida extracts, and their synergistic interaction with fluconazole, against Trichophyton mentagrophytes and Trichophyton rubrum, and to assess their toxicity in vivo model, Galleria mellonella.

\section{Material and Methods}

\section{Clinical specimens}

Clinical isolates (five of each species) of Candida albicans (CA1-CA5), Candida parapsilosis (CP1-CP5), Trichophyton mentagrophytes (TM1-TM5), and Trichophyton rubrum (TR1-TR5), and Candida albicans ATCC 90028 (CAATCC) and C. parapsilosis ATCC 22019 (CPATCC) from Laboratory of Microbiology of São José do Rio Preto Medical School (FAMERP) were used. The isolates were registered in the Brazilian National System of Genetic Resource Management and Associated Traditional Knowledge (SisGen), under the protocol number AF41CDD.

\section{Preparation of the inoculum and extracts}

Each yeast was cultured in Sabouraud Dextrose Agar (SDA, DIFCO $\left.{ }^{\circ}\right)$ and incubated at $35{ }^{\circ} \mathrm{C}$ for 24 hours. Then, inoculums were prepared in $500 \mathrm{~mL}$ Sabouraud Dextrose Broth (DIFCO $\left.{ }^{\circledR}, \mathrm{SDB}\right)$, incubated at $35{ }^{\circ} \mathrm{C}$ for 48 hours, and filtered through a $0.2 \mu \mathrm{m}$ 
Millipore® membrane and submitted to liquid-liquid extraction using ethyl acetate (Synth®) as a counter-phase. The procedure was repeated three times, allowing the total extraction of the fungal metabolites from the culture media. The ethyl acetate phase was completely dried using a rotary evaporator and subsequently solubilized in sterile distilled water with $10 \%$ dimethyl sulfoxide (Synth ${ }^{\circledR}$, DMSO).

\section{In vitro antifungal determination of Candida extracts against dermatophytes isolates}

The antifungal activity of Candida extracts against dermatophytes was evaluated by the broth microdilution technique according to the M38-A2 document protocol, with modifications [14].

The inoculums of dermatophytes were performed after seven days of incubation on potato dextrose agar (Sigma-Aldrich ${ }^{\circledR}$, PDA) at $28^{\circ} \mathrm{C}$. The fungal colonies were covered with $5 \mathrm{~mL}$ of distilled water, and the suspensions were made by scraping the surface with the tip of a sterile loop. The mixture of conidia and hyphal fragments was transferred to sterile tubes and the optical density of the suspensions, at 530 $\mathrm{nm}$, adjusted to $70 \%$ of transmittance. Each suspension was diluted (1:50) with RPMI to obtain the final inoculum concentration of 0.4 to $5 \times 104$ cells $/ \mathrm{mL}$. Aliquots of $100 \mu \mathrm{L}$ were inoculated into 96 well plates containing $100 \mu \mathrm{L}$ of specific extract concentration. Controls were included for the fungal growth and sterility control of culture medium, Candida extracts, and solvent. The microplates were incubated at $37{ }^{\circ} \mathrm{C}$ for 120h. After incubation, the absorbance of the samples was measured by spectrophotometer (Biospectro, SP22, Curitiba, Brazil). The following formula was applied to calculate the percentage inhibition: $\mathrm{I}=1-(\mathrm{AbsT}-\mathrm{AbsC} / \mathrm{AbscGC}) \mathrm{x}$ 100 where: $\mathrm{I}=$ percentage inhibition; AbsT = absorbance of the inoculum with extract; AbsSC = absorbance of sterility control; AbsGC = absorbance of growth control. The MIC of extracts was defined as the lowest concentration inhibiting at least $80 \%$ of the control growth. An aliquot from each well that showed antifungal activity was plated in Petri dishes containing SDA, to determine the minimum fungicidal concentration (MFC). The MFC was defined as the lowest concentration of the extracts that allowed no visible growth on the solid medium [12]. All tests were carried out in triplicate.

\section{Antifungal susceptibility testing for fluconazole}

The antifungal susceptibility test for fluconazole (Sigma-Aldrich ${ }^{\circledR}$ ) was performed according to the M27-A3 document for yeasts and M38-A2 for dermatophytes, with modifications. Regarding the yeasts, the inoculums were prepared according to the turbidity of a 0.5 McFarland standard (corresponding to $1 \sim 5 \times 10^{6}$ colony forming units $(\mathrm{CFU} / \mathrm{mL})$ in Roswell 
Park Memorial Institute (RPMI) 1640 medium. The suspension was diluted with RPMI 1640 to prepare a final inoculum suspension $\left(1 \times 10^{3} \mathrm{CFU} / \mathrm{mL}\right)$. The test was performed in pre-sterilized, flat-bottom 96-well polystyrene plates. The ATCC strains (C. albicans and $C$. parapsilosis) were used as control. The dermatophyte inoculums suspensions were prepared as described above. Fluconazole MIC was defined as the lowest concentration inhibiting at least $50 \%$ for yeast, and $80 \%$ for dermatophytes of the growth, in the relation to the control. According to the CLSI criteria, isolates with fluconazole MIC of $\geq 64 \mu \mathrm{g} / \mathrm{mL}$ were considered as resistant [15].

\section{Checkerboard assay}

The Checkerboard testing method was used to evaluate the combinatory effects of the Candida spp. extracts and fluconazole against $T$. mentagrophytes and $T$. rubrum by a microdilution technique and a spectrophotometric method. Candida extracts and fluconazole were added to the RPMI1640 at serially twofold-diluted concentrations. To assess the nature of the in vitro interactions among Candida extracts and fluconazole, it was calculated the fractional inhibitory concentration index (FICI), according to the formula: (Fluconazole MIC of the mix / Fluconazole MIC alone) + (Extract MIC of the mix / Extract MIC alone). The synergistic interaction was classified using the method described by Kumar et al., in which values of FICI $\leq$
0.5 indicate synergic interactions; $0.5<$ $\mathrm{FICI} \leq 1$, addictive interactions; $1<\mathrm{FICI}$ $\leq 2$, indifferent interactions; and FICI $>$ 2, antagonistic interactions [16].

\section{Toxicity test in Galleria mellonella}

The in vivo toxicity of Candida extracts was tested in G. mellonella model. A total of 10 larvae $(200 \pm 25 \mathrm{mg}$ each) in the sixth-instar of development and absence of cuticle pigmentation were artificially injected with Hamilton micro-syringe $7000.5 \mathrm{KH}$ of $10 \mu \mathrm{L}$ volume. Each larva was injected with 5 $\mu \mathrm{L}$ of Candida extracts at the concentration of $8 \mathrm{mg} / \mathrm{mL}$ into de hemocoel through the last right proleg. Additionally, each larva was bathed for two seconds into the Candida extracts at the same concentration to evaluate the superficial toxicity.

The positive control of the experiment was the injection and bath with quaternary ammonium solution. The Candida extracts solvent control was 10\% DMSO. After the injection and bath, the larvae (treated and control) were incubated at $28^{\circ} \mathrm{C}$, deprived of feed and direct illumination. Throughout the experiment and every $24 \mathrm{~h}$, the larvae were removed from the pre-pupae, in order to delay their metamorphosis. Statistical analyses and graphics were performed by the Log-rank (MantelCox) method in Prism 5 software (GraphPad®) [17]. 


\section{Results}

Minimum Inhibitory Concentration of Candida extracts against dermatophytes

The antifungal activity of Candida extracts is shown in Table 1 . Values of MIC were similar for ATCC and clinical strains. In general, the extracts showed antifungal activity within a MIC range of 31.25 - $2000 \mu \mathrm{g} / \mathrm{mL}$ against the dermatophytes isolates tested. The lowest individual MIC values (31.25 $\mu \mathrm{g} / \mathrm{mL}$ ) were observed for extracts of CP3 and CA6 against TM3, TM4 and TR4.

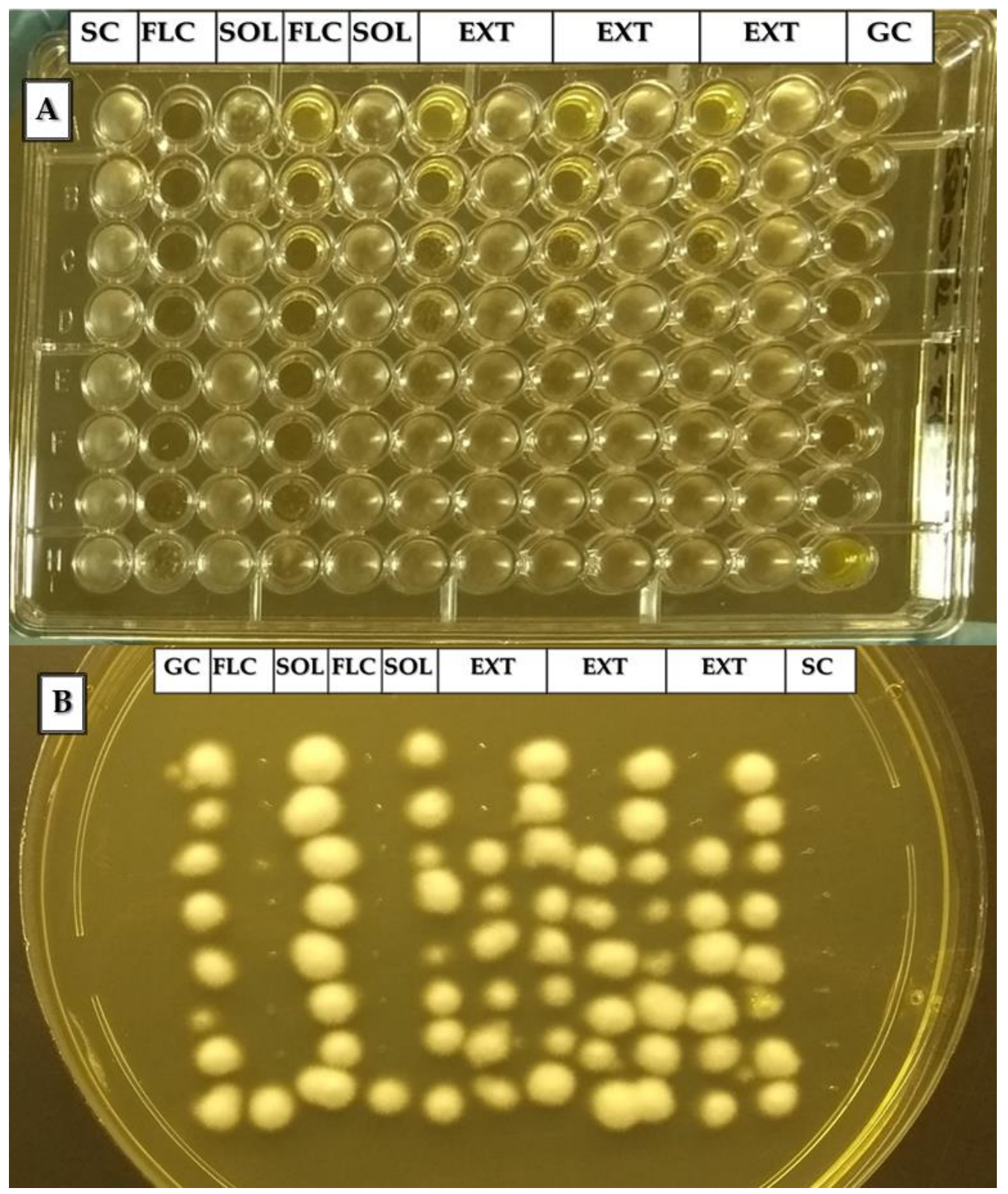

Figure 1: MIC (A) and MFC (B) ( $\mu \mathrm{g} / \mathrm{mL})$ of CP4 extracts against T. rubrum (TR3). SC: Sterility control; FLC: fluconazole; SOL: solvente; EXT: extract; GC: growth control. 
Considering the species in general, according to the geometric means (GM), the best antifungal activity was observed for the C. parapsilosis extracts (GM of $383 \mu \mathrm{g} / \mathrm{mL}$ ). The CP4 extract presented the lowest mean against dermatophytes (GM of 134 $\mu \mathrm{g} / \mathrm{mL})$. On the other hand, C. albicans extracts showed less activity (GM of 732 $\mu \mathrm{g} / \mathrm{mL})$. The best activity of Candida albicans extracts was observed by CA5 extract (GM of $406 \mu \mathrm{g} / \mathrm{mL}$ ) (Table 2). The Candida extracts against dermatophytes in general showed fungicidal properties (MFC) with a value higher than the MIC (range of 500 - $>2000 \mu \mathrm{g} / \mathrm{mL}$, and GM of 1858 $\mu \mathrm{g} / \mathrm{mL}$ ) (Table 1).

Table 1. MICs and MFCs $(\mu \mathrm{g} / \mathrm{mL})$ of Candida extracts against dermatophytes isolates.

\begin{tabular}{|c|c|c|c|c|c|c|c|c|c|c|}
\hline & \multicolumn{10}{|c|}{ Trichophyton mentagrophytes } \\
\hline & \multicolumn{2}{|c|}{ TM1 } & \multicolumn{2}{|c|}{ TM2 } & \multicolumn{2}{|c|}{ TM3 } & \multicolumn{2}{|c|}{ TM4 } & \multicolumn{2}{|c|}{ TM5 } \\
\hline & MIC & MFC & MIC & MFC & MIC & MFC & MIC & MFC & MIC & MFC \\
\hline CAATCC & $>2000$ & $>2000$ & 1000 & 2000 & 2000 & $>2000$ & 2000 & 2000 & 500 & 2000 \\
\hline CA2 & $>2000$ & $>2000$ & $>2000$ & $>2000$ & $>2000$ & $>2000$ & $>2000$ & $>2000$ & 500 & $>2000$ \\
\hline CA3 & 1000 & 2000 & 2000 & 2000 & 2000 & 2000 & 2000 & 2000 & 250 & 2000 \\
\hline CA4 & 2000 & $>2000$ & 2000 & 2000 & 2000 & $>2000$ & 2000 & $>2000$ & 250 & 2000 \\
\hline CA5 & $>2000$ & $>2000$ & 125 & 2000 & $>2000$ & 2000 & 125 & 2000 & 250 & 1000 \\
\hline CA6 & 2000 & 2000 & 2000 & 2000 & 2000 & 2000 & 125 & 2000 & 250 & 1000 \\
\hline СРАТСС & 2000 & $>2000$ & 2000 & 2000 & 2000 & 2000 & 1000 & $>2000$ & 125 & 500 \\
\hline $\mathrm{CP} 2$ & 62.5 & 2000 & 2000 & 2000 & 500 & 2000 & 2000 & 2000 & 250 & 500 \\
\hline $\mathrm{CP} 3$ & 125 & $>2000$ & 250 & 2000 & 1000 & 2000 & 500 & 2000 & 62.5 & 1000 \\
\hline CP4 & 62.5 & 1000 & 250 & 1000 & 31.25 & 1000 & 250 & 1000 & 125 & 250 \\
\hline CP5 & 1000 & 2000 & 250 & 1000 & 1000 & 2000 & 1000 & 2000 & 500 & $>2000$ \\
\hline \multirow[t]{4}{*}{ CP6 } & 1000 & $>2000$ & 500 & $>2000$ & 2000 & $>2000$ & 2000 & 2000 & 500 & 2000 \\
\hline & \multicolumn{10}{|c|}{ Trichophyton rubrum } \\
\hline & \multicolumn{2}{|c|}{ TR1 } & \multicolumn{2}{|c|}{ TR2 } & \multicolumn{2}{|c|}{ TR3 } & \multicolumn{2}{|c|}{ TR4 } & \multicolumn{2}{|c|}{ TR5 } \\
\hline & MIC & MFC & MIC & MFC & MIC & MFC & MIC & MFC & MIC & MFC \\
\hline CAATCC & 500 & 2000 & 1000 & 2000 & 62.5 & 2000 & 31.25 & 1000 & 250 & 2000 \\
\hline CA2 & 1000 & 2000 & $>2000$ & $>2000$ & 250 & $>2000$ & 250 & 1000 & 500 & 2000 \\
\hline CA3 & 2000 & 2000 & 2000 & 2000 & 1000 & 2000 & 500 & 1000 & 500 & 2000 \\
\hline CA4 & 2000 & $>2000$ & 1000 & $>2000$ & 2000 & 2000 & 500 & 2000 & 500 & 2000 \\
\hline CA5 & 250 & 2000 & $>2000$ & $>2000$ & 250 & 1000 & 125 & 1000 & 62.5 & 2000 \\
\hline CA6 & 500 & 2000 & 2000 & $>2000$ & 500 & 1000 & 31.25 & 1000 & 62.5 & 1000 \\
\hline СРАТСС & 125 & $>2000$ & 250 & 2000 & 500 & 1000 & 500 & 1000 & 62.5 & 1000 \\
\hline CP2 & 250 & 2000 & 125 & $>2000$ & 500 & 2000 & 250 & 2000 & 500 & 1000 \\
\hline $\mathrm{CP} 3$ & 31.25 & 2000 & 62.5 & 2000 & 125 & 1000 & 500 & 2000 & 1000 & 2000 \\
\hline $\mathrm{CP} 4$ & 62.5 & 2000 & 1000 & 2000 & 250 & 2000 & 62.5 & 1000 & 125 & 1000 \\
\hline CP5 & 1000 & 2000 & 500 & 1000 & 500 & 1000 & 500 & 1000 & 1000 & 2000 \\
\hline $\mathrm{CP} 6$ & 2000 & 2000 & 1000 & 1000 & 1000 & 1000 & 500 & 1000 & 1000 & 1000 \\
\hline
\end{tabular}


Table 2. Geometric means of MICs and MFCs $(\mu \mathrm{g} / \mathrm{mL})$ of Candida extracts against dermatophytes isolates.

\begin{tabular}{c|cc|cc|cc}
\hline \multicolumn{7}{c}{ Geometric means $(\boldsymbol{\mu g} / \mathbf{m L})$} \\
\hline \multirow{2}{*}{ Extracts } & \multicolumn{2}{c}{ TR } & \multicolumn{2}{c}{ TM } & \multicolumn{2}{c}{ TR/TM } \\
\cline { 2 - 7 } & MIC & MFC & MIC & MFC & MIC & MFC \\
\hline CAATCC & 189 & 1741 & 1516 & 2639 & 536 & 2144 \\
CA2 & 660 & 2297 & 2639 & 4000 & 1320 & 3031 \\
CA3 & 1000 & 1741 & 1149 & 2000 & 1072 & 1866 \\
CA4 & 1000 & 2639 & 1320 & 3031 & 1149 & 2828 \\
CA5 & 287 & 1741 & 574 & 2000 & 406 & 1866 \\
CA6 & 250 & 1189 & 758 & 1741 & 435 & 1439 \\
CPATCC & 218 & 1516 & 1000 & 2000 & 467 & 1741 \\
CP2 & 287 & 2000 & 500 & 1516 & 379 & 1741 \\
CP3 & 165 & 1741 & 250 & 2000 & 203 & 1866 \\
CP4 & 165 & 1516 & 109 & 758 & 134 & 1072 \\
CP5 & 660 & 1320 & 660 & 2000 & 660 & 1625 \\
CP6 & 1000 & 1149 & 1000 & 3031 & 1000 & 1866 \\
\hline
\end{tabular}

MIC: Minimal inhibitory concentration; MFC: minimum fungicidal concentration

Antifungal susceptibility testing of clinical isolates for fluconazole

The MIC values for fluconazole are shown in Table 3. Candida albicans and C. parapsilosis isolates showed MIC values between $0.25-2 \mu \mathrm{g} / \mathrm{mL}$. Among the dermatophytes, higher values were found for T. mentagrophytes (16 - 64 $\mu \mathrm{g} / \mathrm{mL})$, in comparison with T. rubrum
(4 - $8 \mu \mathrm{g} / \mathrm{mL})$. According to CLSI interpretive guidelines, isolates of $C$. albicans, C. parapsilosis and T. rubrum were characterized as susceptible $(S)$ to fluconazole. For T. mentagrophytes, isolates were characterized as susceptible dose-dependent or resistant (Table 3).

Table 3. MICs $(\mu \mathrm{g} / \mathrm{mL})$ of fluconazole against Candida and dermatophytes isolates.

\begin{tabular}{ccc}
\hline Isolates & MIC $(\mu \mathrm{g} / \mathrm{mL})$ & Susceptibility \\
\hline CAATCC & 1 & $\mathrm{~S}$ \\
CA2 & 1 & $\mathrm{~S}$ \\
CA3 & 1 & $\mathrm{~S}$ \\
CA4 & 0.25 & $\mathrm{~S}$ \\
CA5 & 0.25 & $\mathrm{~S}$ \\
CA6 & 0.5 & $\mathrm{~S}$
\end{tabular}




$\begin{array}{ccc}\text { CPATCC } & 0.5 & \mathrm{~S} \\ \text { CP2 } & 1 & \mathrm{~S} \\ \text { CP3 } & 1 & \mathrm{~S} \\ \text { CP4 } & 2 & \mathrm{~S} \\ \text { CP5 } & 1 & \mathrm{~S} \\ \text { CP6 } & 2 & \mathrm{~S} \\ \text { TM1 } & 32 & \mathrm{SDD} \\ \text { TM2 } & 64 & \mathrm{R} \\ \text { TM3 } & 64 & \mathrm{R} \\ \text { TM4 } & 64 & \mathrm{R} \\ \text { TM5 } & 16 & \mathrm{SDD} \\ \text { TR1 } & 8 & \mathrm{~S} \\ \text { TR2 } & 8 & \mathrm{~S} \\ \text { TR3 } & 4 & \mathrm{~S} \\ \text { TR4 } & 8 & \mathrm{~S} \\ \text { TR5 } & 4 & \mathrm{~S}\end{array}$

MIC: Minimal inhibitory concentration; CA: Candida albicans; CP: Candida parapsilosis; TM: Trichophyton mentagrophytes; TR: Trichophyton rubrum; S: Susceptible; SDD: Susceptible dose-dependent; Intermediate; R: Resistant.

\section{Checkerboard assay}

The FICI analyses showed synergistic effects between fluconazole and Candida extracts against dermatophytes. The MIC ranges of fluconazole and extracts, when individually tested, were $4-64 \mu \mathrm{g} / \mathrm{mL}$ and 31.25 - $2000 \mu \mathrm{g} / \mathrm{mL}$, respectively (Figure 2).

The results showed decreased in the MIC ranges for the most combinations tested (Table 4). Consequently, a predominantly synergistic effect (FICI $\leq 0.5$ ) could be observed in the combinations evaluated. Considering the results against $T$. rubrum and T. mentagrophytes together, general GM of FICI was 0.42 . The best antifungal synergistic activities were observed for CA3, CA5, and CA4 with GM of FICI of $0.26,0.28$ and 0.3, respectively (Table 5).

\section{Toxicity test in Galleria mellonella}

In the experiments with larvae bathed in the Candida extracts, there were no statistical differences among extracts, except when compared to the ammonium quaternary toxicity control ( $>$ > 0.05, with 95\% confidence) (Figure 3). Regarding the experiment with the Candida extracts injections, the CA5 extract was the only one that show some 
toxicity, being able to kill $40 \%$ of the larvae $(p=0.023)$ (Figure 4). Thus, results show nontoxicity of Candida of the great majority of the extracts at 8 $\mathrm{mg} / \mathrm{mL}$ in both injection and bath procedure in G. mellonella model.

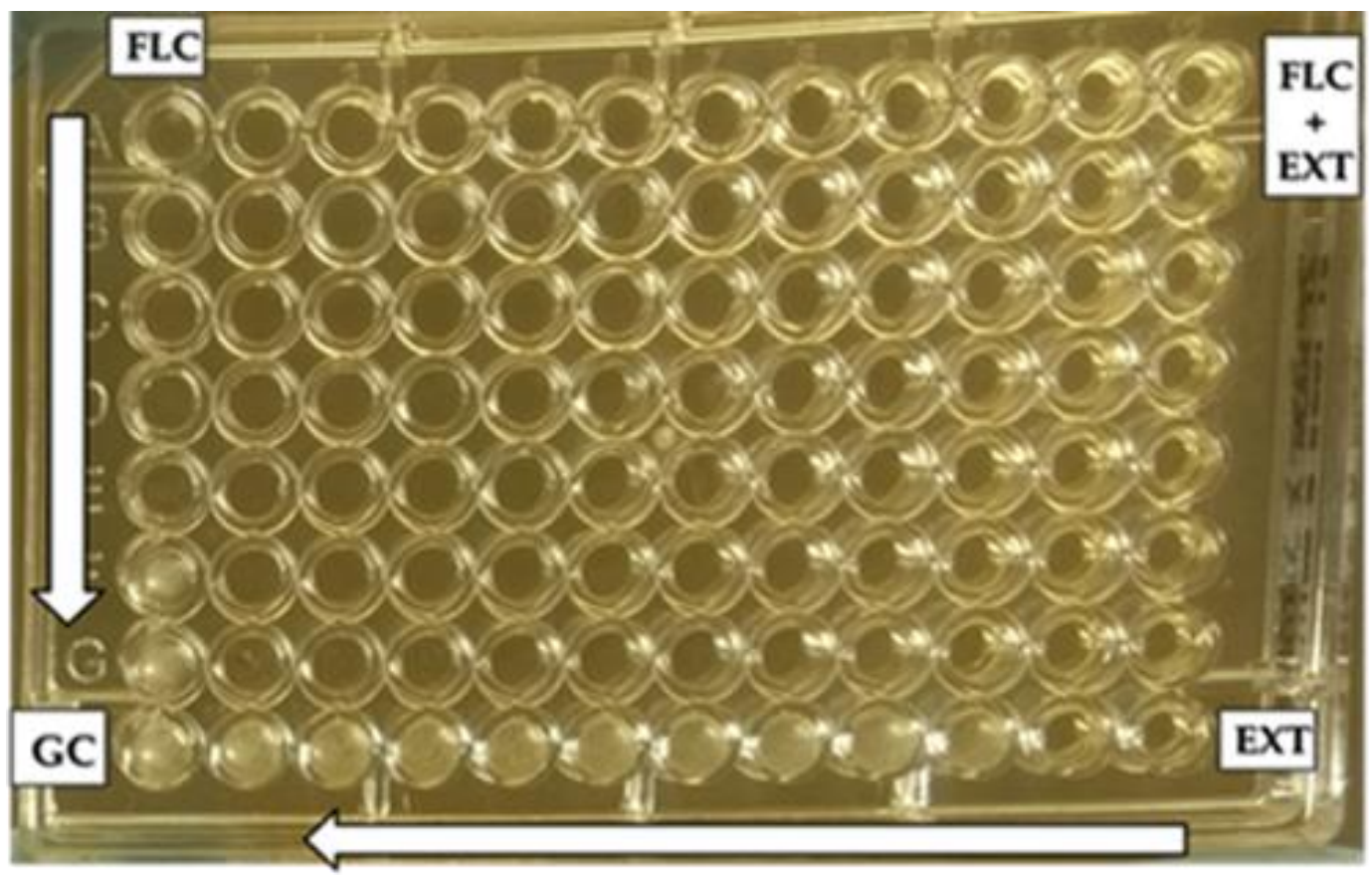

Figure 2: Checkerboard assay - CA2 extract and fluconazol against T. rubrum (TR2), decrease in the MIC range (IFICI 0.03). FLC: fluconazole; SOL: solvente; EXT: extract; GC: growth control.

Table 5. Geometric means of FICIs of Candida extracts against dermatophytes isolates.

\begin{tabular}{c|c|c|c}
\hline \multicolumn{5}{c}{ FICI } & TR & TM/TR \\
\hline CAATCC & TM & 0.44 & 0.46 \\
CA2 & 0.5 & 0.38 & 0.43 \\
CA3 & 0.5 & 0.15 & 0.26 \\
CA4 & 0.44 & 0.25 & 0.31 \\
CA5 & 0.38 & 0.28 & 0.28 \\
CA6 & 0.28 & 0,17 & 0.31 \\
\hline GM & 0.54 & 0.26 & 0.33 \\
\hline CPATCC & 0.43 & & TM/TR \\
\hline CP2 & TM & TR & 0.76 \\
CP3 & 0.76 & 0.76 & 0.38 \\
& 0.6 & 0.24 & 0.71 \\
\hline \hline
\end{tabular}




\begin{tabular}{l|l|l|l}
\hline CP4 & 0.82 & 0.38 & 0.56 \\
CP5 & 0.57 & 0.28 & 0.40 \\
CP6 & 0.76 & 0.25 & 0.43 \\
\hline GM & 0.72 & 0.37 & 0.52 \\
\hline
\end{tabular}
0.42

FICI: fractional inhibitory concentration index; GM: geometric means; GGM: general geometric means.

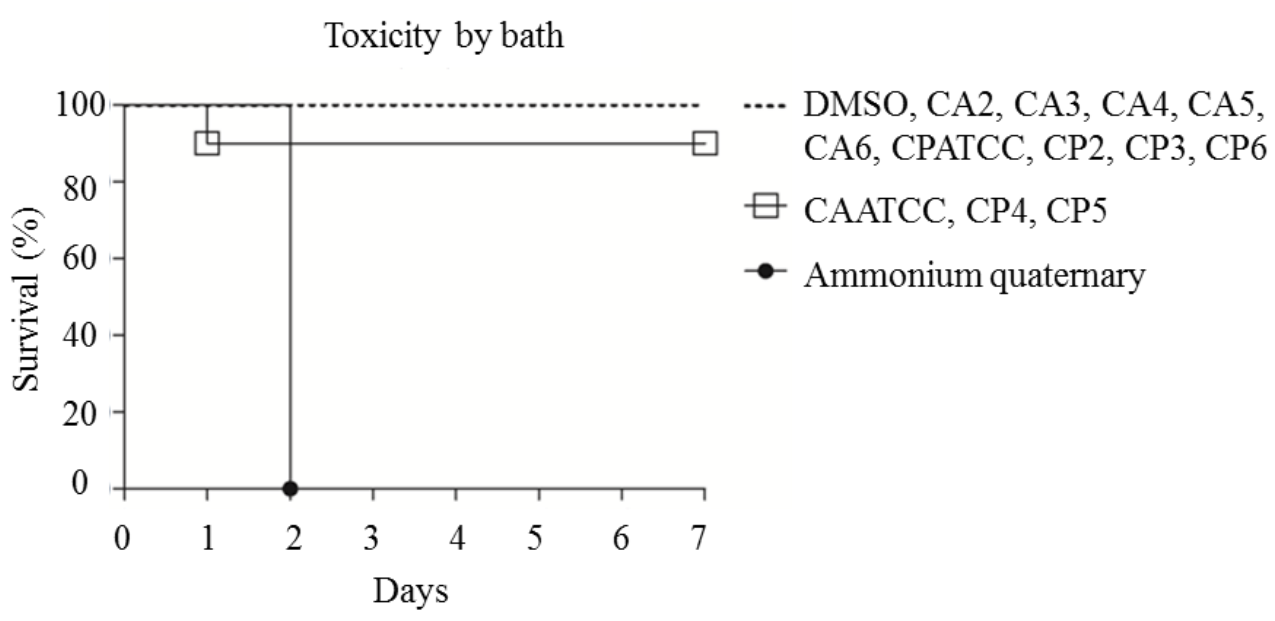

Figure 3. Representation of the survival (\%) of the larvae of Galleria mellonella exposed to the extracts of Candida by bath. Survival was monitored in $24 \mathrm{~h}$ intervals over a period of 7 days.

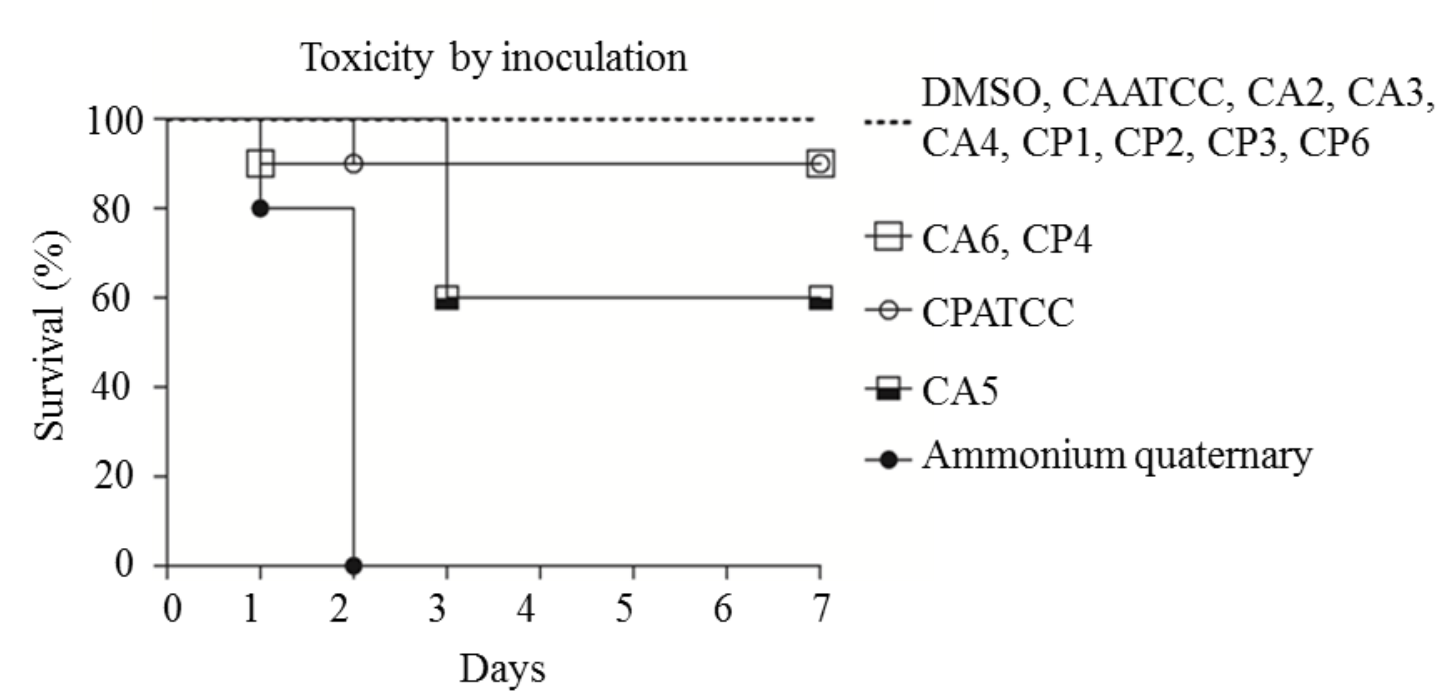

Figure 4. Representation of the survival (\%) of the larvae of Galleria mellonella exposed to the extracts of Candida by injection. Survival was monitored in $24 \mathrm{~h}$ intervals over a period of 7 days. 
In vitro antifungal activity of Candida culture extracts against Trichophyton rubrum

\begin{tabular}{|c|c|c|c|c|c|c|c|c|c|c|c|c|c|c|c|c|c|c|c|c|}
\hline & \multicolumn{20}{|c|}{ Trichophyton mentagrophytes } \\
\hline & \multicolumn{4}{|c|}{ TM1 } & \multicolumn{4}{|c|}{ TM2 } & \multicolumn{4}{|c|}{ TM3 } & \multicolumn{4}{|c|}{ TM4 } & \multicolumn{4}{|c|}{ TM5 } \\
\hline & FLC & EXT & FICI & $\mathrm{CE}$ & FLC & EXT & FICI & $\mathrm{CE}$ & FLC & EXT & FICI & CE & FLC & EXT & FICI & $\mathrm{CE}$ & FLC & EXT & FICI & CE \\
\hline CAATCC & 32 & 2000 & 2 & $\mathrm{I}$ & 32 & 0.001 & 0.5 & $S$ & 32 & 0.001 & 0.5 & $S$ & 32 & 0.001 & 0.5 & S & 2 & 0.001 & 0.12 & $S$ \\
\hline CA2 & 16 & 0.001 & 0.5 & S & 32 & 1000 & 1 & $\mathrm{AD}$ & 32 & 1000 & 1 & $\mathrm{AD}$ & 32 & 0.001 & 0.5 & $S$ & 2 & 0.001 & 0.12 & $S$ \\
\hline CA3 & 16 & 0.001 & 0.5 & $S$ & 32 & 0.0007 & 0.5 & $S$ & 32 & 0.0007 & 0.5 & $S$ & 32 & 0.0007 & 0.5 & $S$ & 4 & 0.0007 & 0.25 & $S$ \\
\hline CA4 & 16 & 0.0007 & 0.5 & $S$ & 32 & 0.0007 & 0.5 & $S$ & 16 & 0.0007 & 0.25 & $S$ & 32 & 0.0007 & 0.5 & $S$ & 4 & 0.0007 & 0.25 & $S$ \\
\hline CA5 & 16 & 0.0007 & 0.5 & $S$ & 8 & 0.07 & 0.12 & $S$ & 16 & 0.03 & 0.25 & $S$ & 32 & 0.0007 & 0.5 & $S$ & 4 & 0.0007 & 0.25 & $S$ \\
\hline CA6 & 16 & 0.001 & 0.5 & $S$ & 32 & 0.001 & 0.5 & $S$ & 32 & 2000 & 1.5 & $\mathrm{AD}$ & 32 & 0.001 & 0.5 & S & 4 & 0.001 & 0.25 & $S$ \\
\hline СРАТСС & 16 & 0.0007 & 0.5 & $S$ & 32 & 0.0007 & 0.5 & $S$ & 16 & 0.0007 & 0.25 & $S$ & 64 & 1000 & 2 & I & 16 & 125 & 2 & I \\
\hline $\mathrm{CP} 2$ & 16 & 0.001 & 0.5 & $S$ & 32 & 0.001 & 0.5 & S & 32 & 0.001 & 0.5 & $S$ & 32 & 0.001 & 0.5 & $S$ & 4 & 250 & 1.25 & $\mathrm{AD}$ \\
\hline $\mathrm{CP} 3$ & 16 & 0.0007 & 0.5 & $S$ & 64 & 250 & 2 & I & 32 & 0.0007 & 0.5 & $S$ & 64 & 500 & 2 & I & 8 & 0.0007 & 0.5 & $S$ \\
\hline CP4 & 16 & 0.001 & 0.5 & $S$ & 64 & 250 & 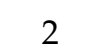 & I & 32 & 0.001 & 0.5 & $S$ & 32 & 125 & 0.5 & $S$ & 8 & 125 & 1.5 & $\mathrm{AD}$ \\
\hline CP5 & 16 & 0.0007 & 0.5 & $S$ & 64 & 250 & 2 & I & 32 & 0.0007 & 0.5 & $S$ & 32 & 0.0007 & 0.5 & $S$ & 4 & 0.25 & 0.25 & $S$ \\
\hline \multirow[t]{4}{*}{ CP6 } & 16 & 0.001 & 0.5 & S & 64 & 0.001 & 1 & $\mathrm{AD}$ & 64 & 2000 & 2 & $\mathrm{I}$ & 32 & 0.001 & 0.5 & S & 8 & 0.001 & 0.5 & $S$ \\
\hline & \multicolumn{20}{|c|}{ Trichophyton rubrum } \\
\hline & \multicolumn{4}{|c|}{ TR1 } & \multicolumn{4}{|c|}{ TR2 } & \multicolumn{4}{|c|}{ TR3 } & \multicolumn{4}{|c|}{ TR4 } & \multicolumn{4}{|c|}{ TR5 } \\
\hline & FLC & EXT & FICI & $\mathrm{CE}$ & FLC & EXT & FICI & CE & FLC & EXT & FICI & CE & FLC & EXT & FICI & CE & FLC & EXT & FICI & CE \\
\hline CAATCC & 4 & 0.07 & 0.5 & $S$ & 2 & 0.001 & 0.25 & $S$ & 2 & 0.0001 & 0.5 & $S$ & 4 & 0.001 & 0.5 & S & 2 & 0.001 & 0.5 & $S$ \\
\hline CA2 & 4 & 0.001 & 0.5 & $S$ & 1 & 0.03 & 0.12 & $S$ & 2 & 0.0001 & 0.5 & S & 4 & 0.001 & 0.5 & $S$ & 2 & 0.001 & 0.5 & $S$ \\
\hline CA3 & 2 & 0.0007 & 0.25 & $S$ & 0.1 & 0.125 & 0.01 & $S$ & 1 & 0.0007 & 0.25 & S & 2 & 0.0007 & 0.25 & $S$ & 2 & 0.0007 & 0.5 & $S$ \\
\hline CA4 & 4 & 0.0007 & 0.5 & $S$ & 0.2 & 0.025 & 0.03 & $S$ & 1 & 0.0007 & 0.25 & 5 & 4 & 0.0007 & 0.5 & $S$ & 2 & 0.0007 & 0.5 & $S$ \\
\hline CA5 & 4 & 0.0007 & 0.5 & $S$ & 0.2 & 0.07 & 0.03 & $S$ & 2 & 0.003 & 0.5 & J & 4 & 0.01 & 0.5 & S & 2 & 0.0007 & 0.5 & $S$ \\
\hline CA6 & 4 & 0.001 & 0.5 & $S$ & 0.1 & 0.03 & 0.01 & $S$ & 1 & 0.001 & 0.25 & $S$ & 2 & 0.001 & 0.25 & S & 2 & 0.0001 & 0.5 & $S$ \\
\hline СРАТСС & 4 & 0.0007 & 0.5 & $S$ & 2 & 0.07 & 0.25 & $S$ & 2 & 0.001 & 0.5 & . & 8 & 1000 & 2 & S & 4 & 500 & 2 & I \\
\hline $\mathrm{CP} 2$ & 4 & 0.03 & 0.5 & $S$ & 0.5 & 0.07 & 0.06 & $S$ & 2 & 0.001 & 0.5 & $S$ & 1 & 0.03 & 0.1 & $S$ & 2 & 0.003 & 0.5 & $S$ \\
\hline $\mathrm{CP} 3$ & 8 & 31.25 & 2 & I & 2 & 0.07 & 0.25 & $S$ & 2 & 0.0007 & 0.5 & S & 4 & 0.0007 & 0.5 & $S$ & 2 & 0.0007 & 0.5 & $S$ \\
\hline CP4 & 4 & 0.001 & 0.5 & $S$ & 2 & 0.003 & 0.25 & $S$ & 2 & 0.5 & 0.5 & $S$ & 2 & 0.0007 & 0.25 & $S$ & 2 & 0.0007 & 0.5 & $S$ \\
\hline CP5 & 2 & 0.03 & 0.25 & $S$ & 1 & 0.03 & 0.12 & $S$ & 2 & 0.001 & 0.5 & $S$ & 2 & 0.001 & 0.25 & $S$ & 2 & 0.0007 & 0.5 & $S$ \\
\hline CP6 & 4 & 0.001 & 0.5 & $S$ & 0.2 & 0.25 & 0.03 & $S$ & 2 & 0.001 & 0.5 & $S$ & 2 & 0.001 & 0.25 & $S$ & 2 & 0.001 & 0.5 & $S$ \\
\hline
\end{tabular}

FLC: fluconazole; EXT: extract; FICI: fractional inhibitory concentration index; CE: combinatory effect (S: synergism; AD; addictive; I: indifferent) 


\section{Discussion and Conclusion}

This study presents the first analysis of biological interference among species of yeast and dermatophytes from nail origin. During our medical and laboratorial practice, it has been observed cases of two morphological types of fungus in the same sample by direct microscopy, but with positive culture just for yeast. It was hypothesized that the yeast, in nutritional competition in the same ecological niche, could produce metabolites with inhibitory properties against dermatophytes, compromising the culture. This event implicates in diagnostic errors, making cases of onychomycoses difficult to control. Considering this hypothesis, this study assessed the potential of metabolites produced by yeasts as antifungal alternatives against onychomycoses and other fungal infections.

Considering the species included in this study, Candida yeast, although part of the natural human microbiota, have been considered, in the last years, as important agents of onychomycosis [1820], and Candida albicans and Candida parapsilosis as the predominant species [21]. Among dermatophytes, T. rubrum and T. mentagrophytes remain prevalent in onychomycosis [22].

Considering cases of mixed infection, the chemical environment in the nail can interfere on microbial survival and evolution of the infection [6, 23-25]. The present research showed that yeast culture extracts have antimicrobial properties against dermatophytes, with MIC values ranging from 31.25 to 2000 $\mu \mathrm{g} / \mathrm{mL}$. Several studies have shown antimicrobial products by different species of fungi [26-28]. However, the parameters tested here are different, with extracts from culture of yeasts in direct contact with dermatophytes.

The MIC values of the Candida extracts against the T. mentagrophytes and T. rubrum were similar. We expected a higher activity of the extracts against $T$. rubrum, since studies indicate that $T$. mentagrophytes has a higher proteolytic activity in comparison to T. rubrum, which is an important virulence factor that gives it an advantage for its rapid mycelial growth [29-31].

The biological individual characteristics of each strain certainly justify the differences in MIC values. Corroborating with this data, Albuquerque et al. emphasized that microorganisms could adapt and respond to the environment with physiological changes as a mechanism of cellular defense or tolerance. A variety of metabolites are generated by multiple stimuli and complex signaling pathways $[32,33]$.

The concomitant presence of dermatophytes and yeasts on the nail plate may arise due to the action of 
In vitro antifungal activity of Candida culture extracts against Trichophyton rubrum

hydrolytic enzymes, produced by some species, facilitating the secondary invasion of others, through a system which may control the expression of genes and cellular processes involved with sporulation, growth and even biofilm formation [34-36].

Several studies have shown antimicrobial molecules isolated from different species of fungi, such as cephalosporins and fusidic acid. The echinocandin family, for example, are an important source of antifungal agents that inhibit the biosynthesis of $\beta-(1,3)-$ glucan, one of the main components of the fungal cell wall, and was first isolated from Aspergillus nidulans [27, 37].

In this study, the extracts produced in these specific conditions showed antifungal activity against dermatophytes, but there was no identification of the components of the extract. Therefore, it was not possible to know the active principle. Further studies are needed to isolate the compounds and identify the chemical classes in which they are inserted, in association with biological assays of biocidal activity. However, these preliminary results are relevant and may lead to the discovery of new drugs.

The high recurrence rates of onychomycosis and the development of new antifungal drugs are challenges to be faced. Fluconazole is an option for systemic treatment of onychomycosis with broad-spectrum, inhibiting lanosterol 14a-demethylase, with in vitro activity against dermatophytes and Candida species. However, the prolonged use has toxicity effects including headache, nausea, rash, abdominal pain, and elevation of transaminases, rarely associated with liver injury or failure [38]. Fluconazole was tested in this study because is an alternative to terbinafine and itraconazole, with advantages in the therapy (lower risk of treatment discontinuation and less adverse events) [39-41]. Thus, the combination of new antimicrobial agents and known drugs has become an alternative to increase the antifungal spectrum and efficacy of these drugs, with reduction of toxicity [42-44]. The combination of Candida extracts used in this study reduced fluconazole MIC values, indicating a synergistic effect of these compounds, which may allow new approaches in the control of fungal infections.

Due to the similarity to the innate immune system of insects and mammals, G. mellonella larvae have been used to investigate the toxicity of new potential antimicrobial compounds [45]. Using this model of study, the activity of new antifungal compounds can be quickly established, informing the need for synthesis of new derivatives or establishing the relative dosage in mammals [46]. In the present study, the nontoxicity of Candida extracts on G. mellonella model enable further investigation of its use for the control of 
In vitro antifungal activity of Candida culture extracts against Trichophyton rubrum

infectious diseases, such as dermatophytoses.

In conclusion, metabolites released by $C$. parapsilosis and C. albicans present antifungal activity against $T$. mentagrophytes and T. rubrum, which may influence the laboratory diagnosis of mixed infections. These results can explain cases of mixed fungal infections where only one of the etiologic agents grows in culture. Furthermore, the isolation and identification of the extracts compounds may allow new therapeutic approaches in the control of fungal infections.

\section{References}

[1] Gupta AK, Versteeg SG, Shear NH. Onychomycosis in the 21st century: an update on diagnosis, epidemiology, and treatment. J Cutan Med Surg. 2017; 21(6): 525-539. doi: 10.1177/1203475417716362.

[2] Vlahovic TC. Onychomycosis: Evaluation, treatment options, managing recurrence, and patient outcomes. Clin Podiatr Med Surg. 2016; 33(3): 305-318. doi: 10.1016/j.cpm.2016.02.001.

[3] Gupta AK, Mays RR. The impact of onychomycosis on quality of life: a systematic review of the available literature. Skin Appendage Disord. 2018; 4: 208-216. doi: 10.1159/000485632.

[4] El-Ganiny AM, Yossef NE, Kamel HA. Prevalence and antifungal drug resistance of nosocomial Candida species isolated from two university hospitals in Egypt, Curr. Med. Mycol. 2021; 7: 31-37. doi: 10.18502/cmm.7.1.6181.

[5] Tosti A, Elewski BE. Onychomycosis: practical approaches to minimize relapse and recurrence. Skin Appendage Disord. 2016; 2(1-2): 83-87. doi: 10.1159/000448056.

[6] Hall GS. Interactions of yeasts, moulds, and antifungal agents: How to detect resistance. 1st ed. Humana Press; 2012.

[7] Rosen T, Friedlander SF, Kircik L, Zirwas MJ, Gold LS, Bhatia N, Gupta AK. Onychomycosis: epidemiology, diagnosis, and treatment in a changing landscape. J Drugs Dermatol. 2015;14: 223-33.

[8] Scorzoni L, de Paula e Silva ACA, Marcos CM, Assato PA, Melo WCMA, Oliveira HC, Costa-Orlandi CB, MendesGiannini MJ, Fusco-Almeida AM. Antifungal Therapy: new advances in the understanding and treatment of mycosis. Front Microbiol. 2017; 23(8): 36. doi: 10.3389/fmicb.2017.00036

[9] Ghannoum M, Isham N. Fungal nail infections (onychomycosis): a neverending story? PLoS Pathog. 2014; 10(6): e1004105.

doi:

10.1371/journal.ppat.1004105

[10] Gupta AK, Daigle D, Carviel JL. The role of biofilms in onychomycosis. J Am Acad Dermatol. 2016; 74(6): 12411246. doi: 10.1016/j.jaad.2016.01.008 
[11] Biasi-Garbin RP, Demitto F de O, do Amaral RCR, Ferreira MRA, Soares LAL, Svidzinski TIE, Baeza LC, YamadaOgatta, SF. Antifungal potential of plant species from brazilian caatinga against dermatophytes. Rev Inst Med Trop Sao Paulo. 2016; 58: 18. doi: 10.1590/S16789946201658018.

[12] De Toledo LG, Dos Santos Ramos MA, Spósito L, Castilho EM, Pavan FR, Lopes EO, Zocolo GJ, Silva FA, Soares $\mathrm{TH}$, Dos Santos AG, Bauab TM, De Almeida MT. Essential oil of Cymbopogon nardus (L.) Rendle: A strategy to combat fungal infections caused by Candida species. Int J Mol Sci. 2016; 17(8): 1252. doi: 10.3390/ijms17081252.

[13] Gupta AK, Studholme C. Novel investigational therapies for onychomycosis: an update. Expert Opin Investig Drugs. 2016; 25(3): 297-305. doi: 10.1517/13543784.2016.1142529.

[14] Clinical Laboratory and Standards Institute. Reference Method for Broth Dilution Antifungal Susceptibility Testing of Filamentous Fungi. Approved Standard-Second Edition, document M38-A2. Clin Lab Stand Inst. 2008; 28: 29.

[15] Clinical Laboratory and Standards Institute. Reference Method for Broth Dilution Antifungal Susceptibility Testing of Yeasts. Approved standard, 3rd edn, document M27-A3. Wayne, PA: Clin Lab Stand Inst. 2008.
[16] Kumar SN, Siji J V., Nambisan B, Mohandas C. Activity and synergistic interactions of stilbenes and antibiotic combinations against bacteria in vitro. World J Microbiol Biotechnol. 2012; 28(11): 3143-3150. doi: 10.1007/s11274012-1124-0.

[17] Renwick J, Daly P, Reeves EP, Kavanagh K. Susceptibility of larvae of Galleria mellonella to infection by Aspergillus fumigatus is dependent upon Stage of conidial germination. Mycopathologia. 2006; 161(6): 377-84. doi: 10.1007/s11046-006-0021-1.

[18] Singal A, Khanna D. Onychomycosis: Diagnosis and management. Indian J Dermatology, Venereol Leprol. 2011; 77(6): 659-672. doi: 10.4103/0378-6323.86475.

[19] Ziccardi M, Souza LOP, Gandra RM, Galdino ACM, Baptista ARS, Nunes AP, Ribeiro MA, Branquinha MH, Santos ALS. Candida parapsilosis (sensu lato) isolated from hospitals located in the Southeast of Brazil: Species distribution, antifungal susceptibility and virulence attributes. Int J Med Microbiol. 2015; 305(8): 848-59.

doi: 10.1016/j.ijmm.2015.08.003.

[20] Subramanya SH, Hamal D, Nayak N, Gokhale S. Case Report Onychomycosis due to Candida parapsilosis in a child with ventricular Septal Defect: An Unusual 
Predisposition. Case Rep Pediatr. 2016, 2016: 4. doi: 10.1155/2016/7026068.

[21] Fich F, Abarzúa-Araya A, Pérez M, Nauhm Y, León E. Candida parapsilosis and Candida guillermondii: Emerging pathogens in nail candidiasis. Indian J Dermatol. 2014; 59(1): 24-29. doi: 10.4103/0019-5154.123485.

[22] Moubasher AH, Abdel-Sater MA, Soliman Z. Incidence and biodiversity of yeasts, dermatophytes and nondermatophytes in superficial skin infections in Assiut, Egypt. J Med Mycol. 2017; 27(2): 166-179. doi: 10.1016/j.mycmed.2017.01.005.

[23] Khosravi AR, Shokri H, Nikaein D, Mansouri P, Erfanmanesh A, Chalangari $\mathrm{R}$, Katalin M. Yeasts as important agents of onychomycosis: In vitro activity of propolis against yeasts isolated from patients with nail infection. J Altern Complement. Med. 2013; 19(1): 57-62. doi: 10.1089/acm.2011.0722

[24] Fatahinia M, Jafarpour S, Rafiei A, Taghipour S, Makimura K, RezaeiMatehkolaei A. Mycological aspects of onychomycosis in Khuzestan Province, Iran: A shift from dermatophytes towards yeasts. Curr Med Mycol. 2017; 3(4): 26-31. doi: $10.29252 / \mathrm{cmm} \cdot 3.4 .26$

[25] Suryawanshi RS, Wanjare SW, Koticha AH, Mehta PR. Onychomycosis: dermatophytes to yeasts: an experience in and around Mumbai, Maharashtra, India.
Int J Res Med Sci 2017; 5(5): 1959-1963. doi: 10.18203/2320-6012.ijrms20171825.

[26] Abdel-Rhman SH, El-Mahdy AM, El-Mowafy M. Effect of tyrosol and farnesol on virulence and antibiotic resistance of clinical isolates of Pseudomonas aeruginosa. Biomed Res Int. 2015; 2015: $456463 . \quad$ doi: $10.1155 / 2015 / 456463$.

[27] Jakubczyk D, Dussart F. Selected Fungal Natural Products with Antimicrobial Properties. Molecules. 2020; 25(4): $911 . \quad$ doi: 10.3390/molecules25040911.

[28] Wang X, Wang Y, Zhou Y, Wei X. Farnesol induces apoptosis-like cell death in the pathogenic fungus Aspergillus flavus. Mycologia. 2014; 106(5): 881-888. doi: 10.3852/13-292.

[29] Pakshir K, Mohamadi T, Khodadadi $\mathrm{H}$, Motamedifar M, Zomorodian K, Alipour S, Motamedi M. Proteolytic activity and cooperative hemolytic effect of dermatophytes with different species of bacteria. Curr Med Mycol 2017; 2(4): 9-14. doi: 10.18869/acadpub.cmm.2.4.9.

[30] Raheem AR, Omolade OA, Folorunso JB, Oluwadun A, Onilude AA. Comparative study of keratinolytic activities of dermatophytes in various keratin substrates. Virol Mycol. 2013; 2(3): 1-3. doi: 10.4172/2161-0517.1000117.

[31] Yue X, Li Q, Wang H, Sun Y, Wang A, Zhang Q, Zhang C. An ultrastructural 
In vitro antifungal activity of Candida culture extracts against Trichophyton rubrum

study of Trichophyton rubrum induced onychomycosis. BMC Infect. Dis. 2015; 15, 532. doi: 10.1186/s12879-015-1240-1.

[32] Albuquerque $\mathrm{P}$, Nicola AM, Nieves E, Paes HC, Williamson PR, SilvaPereira I, Casadevall A. Quorum sensingmediated, cell density-dependent regulation of growth and virulence in Cryptococcus neoformans. MBio. 2013; 5(1), e00986-13. doi: 10.1128/mBio.00986-13.

[33] Albuquerque P, Casadevall A. Quorum sensing in fungi--a review. Med Mycol. 2012; 50(4): 337-345. doi: 10.3109/13693786.2011.652201.

[34] Leonhardt I, Spielberg S, Weber M, Albrecht-Eckardt D, Bläss M, Claus R, Barz D, Scherlach K, Hertweck C, Löffler J, Hünniger K, Kurzai. The fungal Quorum-sensing molecule farnesol activates innate immune cells but suppresses cellular adaptive immunity. MBio. 2015; 17, 6(2): e00143. doi: 10.1128/mBio.00143-15.

[35] Riekhof WR, Nickerson KW. Quorum sensing in Candida albicans: farnesol versus farnesoic acid. FEBS Lett. 2017; 591(12): 1637-1640. doi: 10.1002/1873-3468.12694.

[36] Derengowski LS, De-Souza-Silva C, Braz SV, Mello-De-Sousa TM, Báo SN, Kyaw CM, Silva-Pereira I. Antimicrobial effect of farnesol, a Candida albicans quorum sensing molecule, on Paracoccidioides brasiliensis growth and morphogenesis. Annals of Clin. Microb and Antimicrob. 2009; 8(13). doi: 10.1186/1476-0711-8-13

[37] Al-Fakiha AA, Almaqtrib WQA. Overview on antibacterial metabolites from terrestrial Aspergillus spp. Mycology. 2019; 10(4): 191-209. doi:10.1080/21501203.2019.1604576

[38] Roemer T, Krysan DJ. Antifungal drug development: challenges, unmet clinical needs, and new approaches. Cold Spring Harb Perspect Med. 2014; 1, 4(5): a019703 doi: 10.1101/cshperspect.a019703.

[39] Lima MIO, Medeiros ACA, Silva KVS, Cardoso GN, Lima EO, Pereira FO. Investigation of the antifungal potential of linalool against clinical isolates of fluconazole resistant Trichophyton rubrum. J Mycol Med. 2017; 27(2): 195-202. doi: 10.1016/j.mycmed.2017.01.011.

[40] Lipner SR, Scher RK. Onychomycosis. J Am Acad Dermatol. 2019; 80(4): 853-867. doi: 10.1016/j.jaad.2018.05.1260.

[41] Jiang Y, Luo W, Verweij PE, Song Y, Zhang B, Shang Z, Al-Hatmi AMS, Ahmed SA, Wan Z, Li R, Hoog GS. Regional differences in antifungal susceptibility of the prevalent dermatophyte Trichophyton rubrum. Mycopathologia. 2021; 186: 53-70. doi: 10.1007/s11046-020-00515-z.

[42] Spitzer M, Robbins N, Wright GD. Combinatorial strategies for combating invasive fungal infections. Virulence. 
In vitro antifungal activity of Candida culture extracts against Trichophyton rubrum

2017; 17, 8(2): 169-185. doi: the Multi-user Laboratory (LMU) at São

10.1080/21505594.2016.1196300.

[43] Flores FC, Beck RCR, Silva CB. Essential oils for treatment for onychomycosis: a mini-review. Mycopathologia. 2016; 181(1-2): 9-15. doi: 10.1007/s11046-015-9957-3.

[44] Ahmad A, Wani MY, Patel M, Sobral AJFN, Duse AG, Aqlan FM, AlBogami AS. Synergistic antifungal effect of cyclized chalcone derivatives and fluconazole against Candida albicans. Med Chem Comm. 2017; 8(12): 2195-2207. doi: 10.1039/c7md00440k.

[45] Binder U, Maurer E, Lass-Flörl C. Galleria mellonella: An invertebrate model to study pathogenicity in correctly defined fungal species. Fungal Biol. 2016; 120(2): 288-295. doi: 10.1016/j.funbio.2015.06.002.

[46] Kavanagh K, Sheehan G. The Use of Galleria mellonella Larvae to identify novel antimicrobial agents against fungal species of medical interest. J Fungi. 2018; 4(3): 113. doi: 10.3390/jof403 0113.

Conflict of interest: The author declares no conflicts of interest.

Acknowledgements: Authors would like to the financial support of the National Council for the Improvement of Higher Education (CAPES) and the National Council for Scientific and Technological Development (CNPq), for the scholarships granted. We acknowledge
Jose do Rio Preto (Famerp).

Funding: National Council for the Improvement of Higher Education (CAPES) - 01

How to cite this article: Lemes $\mathrm{TH}$, Torrezan GS, Polaquini CR, Regasini LO, Almeida BG, Brizzotti-Mazuchi NS, Ribeiro MD, Maschio-Lima T, Caetano MH, Pattini VC, Paziani MH, Marcia von Zeska Kress R, Siqueira JPZ, Almeida MTG. In vitro antifungal activity of Candida culture extracts against Trichophyton rubrum and Trichophyton mentagrophytes. Brazilian Journal of Case Reports. 2021 Oct-Dec;01(4):135-152. 